\title{
Exclusión social y nuevas sensibilidades juveniles ${ }^{1}$
}

Jesús Ernesto Urbina Cárdenas²

Recibido:

Mayo 23 de 2012

Aceptado:

Noviembre 25 de 2012

\section{Resumen}

El presente texto expone los resultados preliminares de la investigación sobre la pedagogía emocional de los docentes de la Universidad Francisco de Paula Santander. Desarrolla el objetivo orientado a la comprensión de las nuevas sensibilidades juveniles, inherentes a los jóvenes universitarios participantes del estudio, al igual que la exclusión social, que se cierne como un factor decisivo para el futuro de las nuevas generaciones. Los dos conceptos básicos que sustentan el artículo giran en torno a la idea de joven y exclusión social, jóvenes y nuevas sensibilidades, al igual que un intento de establecer los puntos de encuentro y tensión entres estas dos grandes categorías. En general, aspectos como el consumo y rasgos inherentes a la emocionalidad, conforman los ejes sobre los cuales discurren las páginas que siguen.

Palabras clave: sensibilidades juveniles, exclusión social, complejidad, incertidumbre, inteligencia emocional.

\section{Abstract}

This text presents the preliminary results of the research focused on UFPS teachers' emotional pedagogy. It develops the objective oriented towards the understanding of new youthful sensitivities, which are inherent to the young university students who participated in the study; as well as social exclusion, which establishes itself as a decisive factor for the future of new generations. The two basic concepts that support this article revolve around the idea of youngster and social exclusion, youngster and new sensitivities, as well as an attempt of determining the meeting and tension points between these two main categories. Overall, aspects such as consumerism and emotionalism-inherent features form the core ideas on which the following pages flow.

Keywords: youthful sensitivities, social exclusion, complexity, uncertainty, emotional intelligence. 


\section{Introducción}

$\mathrm{L}$ a investigación titulada "valoración de la pedagogía emocional en los docentes de la Universidad Francisco de Paula Santander de Cúcuta", ha motivado una exploración teórica y epistemológica, con el fin de aproximarse al fenómeno investigado desde la perspectiva de los estudiantes universitarios. Una de estas variables son las sensibilidades juveniles, en el marco de un mundo globalizado, y desde una mirada de la denominada inteligencia emocional (Gardner, 1994; Goleman, 1996; Bisquerra, 2003; De la Torre \& Moraes, 2005; Chabot \& Chabot, 2009).

A esta perspectiva centrada en los afectos, se le agrega el factor de la exclusión social, como un elemento que se cierne sobre tales sensibilidades juveniles, apropiando los debates nacionales e internacionales sobre el alarmante fenómeno de la exclusión a que se ven sometidas las nuevas generaciones. Primero, la dificultad en las comunicaciones con las generaciones adultas, y segundo, la marginalidad y ausencia de oportunidades de los jóvenes para acceder a una vida digna, entre ellas, el empleo (Rodríguez, 2000; Sojo, 2000; Gallart, 2000; Cubides, Laverde \& Valderrama (comp.), 2008; Arango, 2004).

Para estos autores, vivir en este mundo complejo, supone habitar en la incertidumbre. A quienes les ha correspondido habitar el planeta después de dos guerras mundiales catastróficas y asumir la complejidad como parte sustancial de la cotidianidad, no pueden eludir el mote de ser llamados los "hijos de la incertidumbre", haciendo eco a las palabras de Morin (2001) cuando sostiene que, el futuro se llama incertidumbre.

Los "hijos de la incertidumbre" viven en un mundo complejo y planetario. Entendida la complejidad como diferenciación, ritmo acelerado de cambio, ensanchamiento del espectro de posibilidades en el marco de pautas de acción diferenciadas de un contexto a otro, del tiempo de trabajo al tiempo del ocio, de la familia a la comunidad, de las relaciones amorosas a las profesionales. En este abanico de opciones las nuevas generaciones enfrentan el problema constante de elección con nuevos interrogantes: ¿qué debemos hacer en contextos diferentes? ¿Y qué debemos hacer ante la aparición cada vez más usual de nuevos problemas?, pero ante todo, iqué se debe hacer ante este exceso de posibilidades? En definitiva, la paradoja de la incertidumbre estriba en que es imposible no elegir. (Melucci, 2001)

En este mar de incertidumbres, en las cuales, nuevas y viejas generaciones sobreviven, la realidad no es posible objetivarse, pues tal pretensión de objetividad se reduce a los puntos de vista personales del sujeto. El conocimiento por su parte, es una aventura incierta que conlleva en sí misma y permanentemente, el riesgo de ilusión y de error, porque el conocimiento es como navegar en un océano de incertidumbres a través de archipiélagos de certezas (Morín, 2001).

Los jóvenes proyectan sus sueños, empujados por la tensión entre la necesidad de desempeñar un empleo que garantice la sobrevivencia, y la ansiedad que supone un conjunto de nuevas sensibilidades en todos los ámbitos, desde el más serio hasta el más frívolo, desde los más diversos juegos de apariencias hasta el juego político, "tanto en el orden del trabajo como en el orden del ocio, y en las diversas instituciones; en donde la pasión, el sentimiento, la emoción y el afecto vuelven a jugar un papel protagónico". (Maffesoli, 1997, p.27) 
social de los jóvenes contemporáneos y las nuevas sensibilidades que caracterizan su accionar?.

Con base en lo anterior, el propósito de lo que sigue es el de establecer los puntos de encuentro y desencuentro entre dos tópicos que a primera vista parecen antagónicos: la exclusión social y las nuevas sensibilidades de los jóvenes. Por lo tanto, no se trata de la publicación de resultados definitivos de una investigación, sino de una reflexión preliminar sobre estos temas, con el fin de ahondar de forma específica en las culturas juveniles, y en el marco de estas culturas, trazar una ruta que facilite la comprensión de diversos fenómenos inherentes a las sensibilidades de los jóvenes; entre ellas, el tema de la exclusión social, que según varios estudios constituye uno de los principales problemas que afectan a la juventud de hoy (Rodríguez, 2000).

El tema de la exclusión de los jóvenes constituye particularmente un fenómeno que influye sustancialmente en los procesos de desarrollo en nuestros países, y aunque hace parte de la agenda de la mayoría de gobiernos, pareciera que las políticas y las acciones no son suficientes y en el peor de los casos, ineficientes. Los trabajos de Rodríguez (2000), Jacinto y otros (1998), Hopenhayn (2004), Gallart (2003), Kremenchtzky (2000), Garcés (2004), entre otros trabajos, permiten una profundización sobre esta problemática.

Sobre el tema de las sensibilidades de los jóvenes contemporáneos también existe abundante literatura. Para las pretensiones de este trabajo se tomarán como referentes los trabajos de Reguillo (2007), Barbero (2003), Maffesoli (2007), Rubio (2007), Kaplún 2004, Feixa (2006), Urresti (2004), Muñoz (2006). De igual manera, algunos de los artículos publicados en el número 23 de la Revista Nómadas (2005), y finalmente el texto publicado por la Universidad Central "viviendo a toda" (2008), entre otros trabajos relevantes.

\section{Jóvenes y exclusión social}

Se entiende la exclusión social como el proceso por el cual a ciertos individuos y grupos, se les impide sistemáticamente el acceso a posiciones que les permitirían una subsistencia digna dentro de los niveles sociales establecidos por las instituciones y valores en un entorno dado. De igual modo, es importante aclarar que la exclusión social es un proceso, no una condición. Sus fronteras cambian, y quién es excluido o incluido puede variar con el tiempo, "dependiendo de la educación, las características demográficas, los prejuicios sociales, las prácticas empresariales y las políticas públicas” (Gallart, 2000).

Los caminos hacia la exclusión son variopintos. Por ejemplo, es posible según Gallart $(2000,61)$, que:

"...el analfabetismo funcional, la condición de ilegal, la imposibilidad de pagar el alquiler, lo que induce la carencia de techo, o la pura mala suerte con un jefe o un policía, desaten una cadena de acontecimientos que lleven a una persona (y a su familia, con mucha frecuencia) a arrastrarse a la deriva hacia las regiones exteriores de la sociedad, habitadas por los despojos de la humanidad fracasada. La exclusión no sólo produce la imposibilidad de acceder a satisfacer las necesidades básicas, sino que el proceso de exclusión social y la insuficiencia de las políticas reparadoras de integración conducen a una integración perversa [que] hace referencia al proceso laboral en la economía criminal". (Gallart, 2000, p. 61)

"Exclusión social" indica entonces la existencia de una vinculación pobre, o de una vinculación parcial -deficitaria- a la comunidad de los valores que caracterizan un grupo social determinado, lo cual implica que no se cuenta con los medios y recursos básicos para asegurar un nivel de vida con calidad. "En cuyo caso puede hablarse también de exclusión económica, política, 
de género, étnica y ambiental para citar solo las dimensiones más gruesas del pensamiento social contemporáneo". (Sojo, 2000, p. 50)

Se puede afirmar que a pesar de la incorporación del tema en las agendas de la mayoría de gobiernos del mundo y en específico de los gobiernos de Latinoamérica, el problema de la exclusión social de los jóvenes sigue constituyendo uno de las mayores preocupaciones para las agencias e investigadores del tema. De acuerdo con Rodríguez (2000), estos avances significativos no corresponden con los resultados, por lo que se hace indispensable encarar los siguientes núcleos problémáticos:

En primer lugar, se evidencia ineficiencias e ineficacias de las instituciones responsables del diseño e implementación de las políticas encaminas a resolver este asunto.

De igual forma, la pertinencia de las propuestas no siempre corresponden con los problemas particulares de cada país o región.

Aún existen limitaciones de recursos y falta una voluntad explícita de los Estados para resolver problemas puntuales en cuanto a la exclusión de la población joven de mejores oportunidades sociales.

De igual manera, los chicos de estratos populares urbanos experimentan un nivel de riesgo de exclusión social que tiende a centralizar la pobreza entre los jóvenes, fruto de la confluencia de los siguientes factores:

"(1) la creciente incapacidad que exhibe el mercado de trabajo para absorber personas con escasas calificaciones y para garantizar la cobertura de prestaciones sociales tradicionalmente ligadas al desempeño de empleos estables; (2) las dificultades que enfrenta el Estado para reformar la educación y los sistemas de capacitación a un ritmo ajustado a los requerimientos por nuevas aptitudes y destrezas; (3) las transformaciones en las familias y en la composición de los vecindarios (...) afectadas por una reducción de su competencia para generar estímulos y confianza en niños y jóvenes sobre las virtudes asociadas a la inversión de esfuerzos en la educación como el medio privilegiado para alcanzar las metas deseadas; (4) la emancipación temprana de los jóvenes de niveles educativos bajos y tasas de fecundidad más altas que la de sus pares con niveles educativos superiores, cuya acción contribuye a que la pobreza se concentre en las primeras etapas del ciclo de vida familiar; (5) la segregación residencial, por la cual se produce una creciente concentración espacial de hogares con similares niveles de vida, homogeneizándolos hacia adentro y distanciándolos hacia fuera; (6) la separación de los espacios públicos de sociabilidad informal fuera del mercado, lo que reduce la frecuencia de encuentros cara a cara entre personas de distinto origen socioeconómico; y (7) la segmentación de los servicios básicos, entre los que se destaca especialmente -por su significación en estos temas- el caso de la educación" (Rodríguez, 2002, p. 32-33).

Lo anterior trae como consecuencia, en primera instancia, el impedimento para que tanto el sistema educativo como el sistema laboral operen como transmisores de normas y valores que ordenen la vida cotidiana, estructuren aspiraciones y definan metas a alcanzar. De otra parte, la inestabilidad e incompletitud de las familias reducen la capacidad de los jóvenes en su proceso de socialización, transformando el "aislamiento social" en un auténtico "hueco normativo" que deteriora las percepciones sobre las instituciones. ISSN 0122-820X

De acuerdo con Rossana Reguillo (2001, p. 9), la juventud sufre dos procesos de estigmatización social y política que contribuyen a este panorama incierto: la exclusión y la "demonización". Existe una tendencia social ampliamente difundida por los medios de información masiva a relacionar los jóvenes con problemas de delincuencia, consumo de sustancias psicoactivas, pandillas, etc. De igual modo, esto genera "una reacción "en blanco" por parte de los chicos que se expresa en una profunda desconfianza frente a la política formal, su desencanto ante prácticamente cualquier 
forma de participación institucionalizada" y el pragmatismo con el que suelen resolver las opciones electorales. Sin embar-go, sus actitudes y acciones configuran nuevas identidades culturales caracterizadas por un profundo "espíritu de lo político", en consonancia con la afirmación de Beck de que "los jóvenes practican una denegación de la política altamente política".

La mezcla de todos estos factores, según el informe de la CEPAL-OIJ $(2004,107)$, contribuye a la formación de subculturas marginales, de pandillas y barras bravas que construyen sus propios códigos y relatos para irrumpir en el ámbito social y político, convirtiéndose en víctimas y victimarios de un espiral que pareciera ser infinito y que se resume en tres elementos: inseguridad pública, exclusión juvenil e ineficiencias normativas, que en la mayoría de los casos no figuran claramente en las prioridades para la formulación de políticas públicas para este sector.

El documento de la CEPAL-OIJ (2004, p. 17-21), destaca diez "tensiones y paradojas", que resumen de forma concisa los problemas recurrentes relacionados con la exclusión de los jóvenes en Iberoamérica:

- En la actualidad los jóvenes tienen mayores posibilidades para escolarizarse pero de igual manera triplican los índices de desempleo respecto a las generaciones precedentes: mayor escolaridad y menores posibilidades de empleo.
- La juventud tiene proporcionalmente mayor participación en redes informáticas, y más acceso a información merced a su alto nivel de escolarización y de consumo de los medios de comunicación. Pero participan menos de espacios decisorios de la sociedad, sobre todo en la esfera del Estado: más informados pero menos participación en las decisiones del Estado.

- Los jóvenes están más socializados en nuevos valores y destrezas, pero más excluidos de los canales para traducirlas en vidas autónomas y realización de proyectos propios: mayores destrezas en lo socialcomunicativo pero dificultades para ejercer su autonomía.

- Los jóvenes viven un contraste entre buena salud y riesgos sanitarios poco cubiertos. Tanto desde la perspectiva de la atención hospitalaria, como de la prevención de riesgos, la juventud enfrenta un vacío: buena salud vs riesgos sanitarios.

- Los y las jóvenes latinoamericanos deben migrar a otros países en busca de mejores oportunidades de empleo pero sufren las restricciones propias del migrante: migración vs exclusión.

- Los nuevos patrones de consumo cultural de la juventud, provee de íconos y referentes que permiten a gran parte de este grupo etario generar identidades colectivas y participar de universos simbólicos. Por otra parte, se trata de identidades poco consolidadas, fragmentarias, a veces bastante cerradas, que contrastan con las crecientes dificultades para armonizarse con el resto de la sociedad, particularmente con la población adulta y las figuras de autoridad: distancia entre nuevos consumos culturales y la realidad social en que viven los jóvenes.

- Los jóvenes parecen ser más aptos para el cambio productivo pero más excluido de este. Los principales signos de estos tiempos son la institucionalización del cambio y la centralidad del conocimiento como motor del crecimiento, y ambos factores colocan a la juventud en una situación privilegiada para aportar al desarrollo, sin embargo, los jóvenes tienen restricciones para acceder en la práctica a los grandes cambios productivos: cambios productivos vs exclusión.

- La juventud ostenta un lugar ambiguo entre receptores de políticas y protagonistas del cambio: por una parte la sociedad proyecta 
al joven desde apreciaciones prejuiciados como "carentes", "vulnerables", "capital humano", población a proteger o racionalizar, a empoderar o controlar. Pero en la práctica los jóvenes se vuelcan sobre sus mundos de vida de manera más cotidiana y menos épica, generando nuevas sensibilidades y produciendo nuevas identidades.

- La expansión del consumo simbólico y la restricción en el consumo material. Los jóvenes quedan expuestos a un amplio abanico de posibilidades de consumo, y la cultura juvenil cobra mayor presencia en los cambios de sensibilidad de las sociedades iberoamericanas. Pero gran parte de los y las jóvenes no logran la movilidad social anhelada.

Autodeterminación y protagonismo, por una parte, y precariedad y desmovilización, por otra. Es decir, que a pesar del aparente reconocimiento social y político de los y las jóvenes, en el mundo real las exigencias cada vez más excluyentes impiden la autodeterminación juvenil.

Parte de estas tensiones se refleja en las encuestas de hogares aplicada en el 2002 en 18 países de Latinoamérica, en donde se ratifica este fenómeno de exclusión: la pobreza alcanza el $41 \%$, equivalente a aproximadamente 58 millones, de los cuales 21 millones aproximadamente son "pobres extremos". En términos absolutos -sostiene el informe- en el 2002 habría 7 millones 600 mil jóvenes pobres más que 1990 . En relación con el corte rural-urbano, en el año 2002 la pobreza alcanzaba a uno de cada 3 jóvenes urbanos latinoamericanos entre los 13 países analizados, mientras que dicha proporción es un $64 \%$ superior entre los jóvenes rurales. Por su parte, la indigencia juvenil de la ciudad es inferior a $10 \%$, mientras que supera el $27 \%$ entre los rurales. Así, estos últimos tienen una probabilidad 3,1 veces superior de vivir en condición de pobreza. Cabe hacer notar, por último, que estas diferencias de pobreza e indigencia por corte rural-urbano en América
Latina no son privativas de los jóvenes, sino que atraviesan a toda la población. (CEPALOIJ, 2004, 121)

El informe CEPAL-OIJ $(2004,110)$ destaca ocho causas que inciden en el fenómeno de la situación de exclusión de los jóvenes:

- La educación: no obstante los esfuerzos desplegados en los países, se mantienen bajos niveles de cobertura y calidad en los sistemas educativos formal y no formal, presentando una desvinculación del mercado de trabajo y de la realidad de los alumnos.

- El mercado de trabajo muestra mayor incapacidad para absorber la oferta de mano de obra juvenil, ya sea por su baja calificación y experiencia o por la mala calidad de la mayoría de los puestos de trabajo que se generan (informales, precarios y de bajos ingresos).

- La familia presenta transformaciones e irregularidades de estructura y estabilidad, que están presentes en los hogares de la mayoría de los jóvenes pobres, con consecuencias asociadas a violencia, carencias afectivas y materiales. ISSN 0122-820X

- El embarazo adolescente es una causa recurrente en la reproducción y feminización del círculo de pobreza.

- La ruralidad se asocia a una falta de incentivos y programas para retener la migración de los jóvenes a la ciudad.

- La segregación espacial urbana, donde se concentra la mayor cantidad de población joven, con servicios básicos deficientes o nulos, altos índices de violencia y falta de mecanismos de institucionalización, todo lo cual da lugar a la creación de subculturas juveniles, muchas veces signadas por la violencia o la infracción a la ley.

- La discriminación por razones etarias, por parte de un mundo adulto que no acepta o 
condena los espacios y símbolos culturales propios de la juventud, a lo que se suman las discriminaciones étnicas o de género que afectan a las posibilidades de integración y desarrollo de muchos jóvenes. Ser joven, pobre, indígena (o negro) y mujer es una barrera casi imposible de sortear, que condena a reproducir la exclusión de una generación a la siguiente.

- La violencia y la droga son problemas cada vez mayores en las ciudades iberoamericanas, y actúan simultáneamente como causa y consecuencia de la precariedad social y económica en que viven los jóvenes.

Este panorama de exclusión de los jóvenes avizora una situación no muy clara para el desarrollo de Latinoamérica, sujeta por un lado a las exigencias de la banca mundial, y por otra, a la realidad social y política de estos países signados por la desigualdad y la eclosión de complejos problemas. Hopenhayn (2004) sostiene la necesidad de proponer otra mirada integrada al fenómeno, dada la combinación explosiva de situaciones en lo laboral, en lo educativo, en lo económico y en lo social, generando en los jóvenes un desinterés para la participación en el ámbito político. Se requiere la construcción de un tránsito de la juventud como protagonistas del cambio político y social, bajo la concepción de los jóvenes como sujetos de derecho y objeto de políticas.

En este marco se propone a continuación una mirada a las emergencias de las nuevas sensibilidades juveniles con el fin de establecer rutas posibles para una lectura menos prejuiciosa del tema.

\section{Jóvenes y nuevas sensibilidades}

"...existe un hedonismo de lo cotidiano, irreprimible y potente, que subtiende y sostiene a toda vida en sociedad."
(Maffesoli, "en el crisol de las apariencias")

La exclusión social sería parte del collage en la cual emerge esa nueva manera de amar y de sentir de nuestros jóvenes. En el bricolaje donde se ubican las nuevas sensibilidades, no sólo caben nuevas maneras de percibir y actuar en el mundo, también se "encriptan" los graves problemas de marginación y estigmatización de la población juvenil. Es de lo que se quiere hablar en las líneas siguientes.

Un primer interrogante puede ayudar a esta reflexión: icuáles son esas nuevas sensibilidades ante la emergencia de esta tensión entre la mirada particular de los jóvenes y los procesos de exclusión social en que viven? Vale la pena, entonces, situarse en la época contemporánea y considerar algunas tendencias alternativas que según Maffesoli (2007), caracterizan a la posmodernidad desde siempre.

La época que nos ha correspondido vivir es particularmente transgresora en el sentido de cuestionar el racionalismo moderno, y lo cuestiona a través de la configuración de una "cultura dominante", que se manifiesta en la presencia y co-existencia de un abanico de rasgos diferentes, pero subordinados unos de otros (Grosser Guillén, 2006):

- Nueva superficialidad: nueva cultura de la imagen, estética y simulacro.

- Nuevo tipo de emocionalidades: "intensidades" basadas en lo individual hedonista.

- Debilitamiento de la historicidad.

- Sólo el presente es relevante, ya no importa el futuro.

- Proceso de personalización marcado por un sesgo narcisista y hedonista que acentúa el individualismo.

- La consigna del sujeto es "mantenerse joven y hermoso".

- Se encumbra el placer y el cuerpo.

- La "juventud" se considera una mercancía.

- Aparición de la "mercadotecnia emocional". 
Rasgos que parecieran encontrar su propia expresión en las culturas juveniles, y que su sentido puede evidenciarse en las múltiples formas como se muestran los jóvenes en su cotidianidad. Un mundo " post" cargado de inciertas verdades que se multiplican en lo que Maffesoli (2007) denomina la "armonía de los contrarios", donde el conflicto, el desorden, la disfunción vienen finalmente a confirmar a sus opuestos: en suma, una organización social que no se basaría en la búsqueda de grandes soluciones, en la resolución de problemas inherentes a toda vida en sociedad, sino que, por el contrario, aprendería acomodarse a ellos, que buscaría utilizarlos para un aumento de vitalidad.

Pero en la contraparte, operan rasgos diluyentes, ya no sujetos al hilo conductor de la racionalidad, sino construidos a partir de un complejo proceso de atracciones, repulsiones, emociones y pasiones, donde el factor "consumo" junto a las categorías identitarias del mercado rampante como "capacidad adquisitiva", "nivel de consumo", actúan como lazos de fuerza exocéntricos con puntos de apoyo en los bordes, que en lugar de incluir, se convierten en factores de exclusión especialmente para la población juvenil. Ser o parecer joven tiene hoy valor agregado: "el que le asignan los medios y la publicidad, por supuesto. Pero también y sobretodo, el que adquieren recientemente, cuando los y las jóvenes se hacen visibles en los nuevos paradigmas culturales" (Muñoz, 2000, p. 4). En el medio de esta puja entre "fuerzas del mercado" y "ser o parecer joven", encuba un exótico híbrido mitad indigente, mitad joven contemporáneo.

En este ámbito de la postmodernidad los conceptos que parecen identificar la figura del joven, se asocian con la producción, la circulación y el consumo de significaciones. El problema que se cierne sobre esta mapa semántico en el cual se mueven las culturas juveniles, es que "producir", "circular" y “ "consumir", son sentencias letales para los jóvenes, que ven estrellar sus ilusiones en un mar turbulento de falta de oportunidades, que por lo general lo condenan a la indigencia.

Pedroza y Villalobos (2006) identifican cuatro aspectos relevantes de lo que denominan la "juventud postmoderna":

- Territorio movedizo de identidades

- Travesía entre la adaptación y la resistencia activa y pasiva.

- Emprendimiento y empresarialización de la subjetividad

- Rupturas de la felicidad entre el discurso y la realidad

Estos rasgos suponen la configuración de un mundo movedizo, incierto, en el cual cabe todo y nada a la vez, territorios gelatinosos que como las arenas movedizas se tragan y desaparecen a quienes osen pisar sus fronteras variopintas: la indigencia, el consumo de sustancias psicoactivas, el ingreso a bandas delincuenciales, obrarían como claras consecuencias de estos infiernos "post" que tienden su alfombra roja en nuestros países tercermundistas.

En este nicho de incertidumbres, emerge la posibilidad del trayecto, la travesía hacia el territorio de los abismos transitorios en el cual los jóvenes alimentan su rebeldía y su furia creativa, o la simple vuelta de espalda para ignorar el problema, pues el rompimiento con lo político, la saturación de los grandes ideales lejanos, la fragilidad del proyecto moral de occidente, convergen en la perenne travesía hacia un futuro cuya única certeza es la incertidumbre. ISSN 0122-820X 
Si esto es así, los jóvenes no serían sólo el fruto de una nueva sensibilidad per se, fruto del tiempo que les ha correspondido vivir, sino del "modus operandi" de una nueva forma de conocer y producir conocimiento, en el cual, la exclusión actuaría como un elemento más en el complejo engranaje social que deconstruye y reconstruye un nuevo mundo.

\section{Tensiones y puntos de encuentro}

Surge de manera contundente como punto central sobre el cual convergen las fuerzas opuestas entre nuevas sensibilidades y exclusión social, el consumo. Por un lado, el consumo visto como la acción diabólica del mercado y sus catastróficas consecuencias; y por otro el consumo, como una manera de manifestar el joven sus sensibilidades contemporáneas. Y desde ese mismo ámbito, una nueva episteme que enraíza sus orígenes en una estética, en el surgimiento de un "homo estheticus".

La consumación -afirma Maffesoli- por oposición a la simple acción de consumir es eso que han encontrado los etnólogos en diversas culturas, donde no es más lo económico lo que predomina, no es más la economía de sí, ni la economía del mundo:

Lo que caracteriza ahora al mundo es gastar, el despilfarro de los afectos, el despilfarro de emociones, el desperdicio de los objetos y, finalmente, de las capacidades financieras, (...). Si hay un imaginario del gasto, del despilfarro, del lujo, de eso que yo llamo el consumismo, entonces siempre se encuentra el medio para desperdiciar. Se encuentra siempre lo que es necesario quemar, porque lo propio de la consumación es el hecho de quemar los afectos, quemar los objetos. (Maffesoli, 2004, p. 40)

Lo cual, según Maffesoli, haría parte de la urdimbre de unas prácticas juveniles que dan cuenta de un cierto salvajismo del mundo, pero que de igual manera provocarían la nueva vivencia: aquella donde sería posible pensar el conocimiento como un arte. (Maffesoli, 2004)

Es decir, un imperio del consumo que puede leerse como camino expedito hacia la exclusión, pues no todos los jóvenes tienen los medios necesarios para consumir afectos; y el consumo como un camino que abre múltiples posibilidades para la creación, el arte y las nuevas epistemes. El joven consume lo que le apetece, y si el mercado no lo ofrece, su infinita inventiva le propiciaría las herramientas para forjar un nuevo mundo. A mayor exclusión, mayor inventiva. Lo cual no deja de ser una pérfida manera de conformismo a ultranza.

Aparte del consumo como característica importante del mundo postmoderno, Raúl Zarzuri Cortés (2000, p. 12), siguiendo a Maffesoli propone cuatro rasgos básicos de lo que, según estos autores señalan como "neotribalización":

a) Comunidades emocionales: lo determinante de este elemento se vincula al carácter predominantemente afectivo/emotivo que se fragua al interior de estas agrupaciones, remodulando - frenando - el imperio de la racionalidad formal -instrumental, productiva y calculabilista- que predomina en la intemperie de las grandes metrópolis contemporáneas.

b) Energía subterránea: en este punto la inercia, la verticalidad y la uniformidad que caracteriza al continum de la sociedad actual se ve resquebrajado por una multiplicidad de léxicos - prácticas sociales polisémicas y alternativas - cuyo contenido se expresa a través de una grupalidad experiencial o un vitalismo que sitúa su flujo más allá del eje individualismo/ muchedumbre.

c) Sociabilidad dispersa: bajo esta noción lo social emerge como un discurso omnipresente y que se expresa a través de relaciones contractuales urbanas entre individuos -mayoritariamente adultos - que comparten los patrones culturales y sociales definidos por el saber hegemónico (discurso apolíneo). Mientras que soterrada $e$ intersticialmente se abre paso un discurso 
discontinuo y fragmentario (discurso dionisiaco) - expresión de un saber parcial_ que se opone a la lógica dominante, asumiendo estrategias de interacción diversificantes que fundan una nueva socialidad neotribal.

d) Fisicidad de la experiencia: el espacio físico - la urbe - se transforma aquí en un factor determinante en la conformación del entramado biográfico intersubjetivo. El espacio como artificio cultural que permite "formatear» la dimensión existencial del ser. Lo significativo aquí parece ser que a mayor globalización y cosmopolitismo metropolitano, mayor seráel deseo de identificación espacial localista e intimista. (Zarzuri Cortés, 2000, p. 12)

Rasgos que cobran su propia vitalidad en el quehacer cotidiano de las nuevas generaciones. Al respecto, Jesús MartínBarbero sostiene como estos cambios apuntan a la emergencia de sensibilidades "desligadas de las figuras, estilos y prácticas de añejas tradiciones que definen 'la cultura' y cuyos sujetos se constituyen a partir de la conexión/desconexión con los aparatos". En la empatía de los jóvenes con la cultura tecnológica, que va de la información absorbida por el adolescente en su relación con la televisión a la facilidad para entrar y manejarse en la complejidad de las redes informáticas, lo que está en juego es una "nueva sensibilidad hecha de una doble complicidad cognitiva y expresiva: es en sus relatos e imágenes, en sus sonoridades, fragmentaciones y velocidades que ellos encuentran su idioma y su ritmo". (Barbero, 2003, p.4)

Lo cual permite la emergencia de un sensorium nuevo, unos nuevos modos de percibir y de sentir, de oír y de ver, que en muchos aspectos choca y rompe con el sensorium de los adultos:

Un buen campo de experimentación de estos cambios y de su capacidad de distanciar a la gente joven de sus propios padres se halla en la velocidad y la sonoridad. No solo en la velocidad de los autos, sino en la de las imágenes, en la velocidad del discurso televisivo, especialmente en la publicidad y los videoclips, y en la velocidad de los relatos audiovisuales. Y lo mismo sucede con la sonoridad, con la manera como los jóvenes se mueven entre las nuevas sonoridades: esas nuevas articulaciones sonoras que para la mayoría de los adultos marcan la frontera entre la música y el ruido, mientras para los jóvenes es allí donde empieza su experiencia musical. Una segunda dinámica, que hace parte del ecosistema comunicativo en que vivimos, se anuda pero desborda el ámbito de los grandes medios, se trata de la aparición de un entorno educacional difuso y descentrado en el que estamos inmersos (Barbero, 2003, p. 7).

Este conjunto de rasgos definen claramente un "cambio de época" en el cual los adultos aun no alcanzan a asimilar porqué los padres ya no son el centro articulatorio de la formación de los jóvenes, la escuela no es el único lugar para aprender y el libro tampoco es el medio natural para comunicar el conocimiento. Un mundo que se complejiza y donde juegan múltiples variables que para los jóvenes, situados en los márgenes de la sociedad, pese a las diferencias de clase, de género, de emblemas aglutinadores, comparten un conjunto de características que según Reguillo (2003), definen las culturas juveniles en este nuevo siglo:

1. Poseen una conciencia planetaria, globalizada, que puede considerarse como una vocación internacionalista. Nada de lo que pasa en el mundo les es ajeno, se mantienen conectados a través de complejas redes de interacción y consumo.

2. Priorizan los pequeños espacios de la vida cotidiana como trincheras para impulsar la transformación global. ISSN 0122-820X

3. Existe un respeto casi religioso por el individuo que se convierte en el centro de las prácticas. Puede decirse que la escala es individuo-mundo y que el grupo de pares no es ya un fin en sí mismo, sino una mediación que debe respetar la heterogeneidad.

4. Selección cuidadosa de las causas sociales en las que se involucran. 
5. El barrio o el territorio han dejado de ser el epicentro del mundo.

Con Reguillo (2003) pueden encontrarse puntos de encuentro significativos a la hora de establecer aproximaciones y tensiones entre los discursos sobre exclusión social y los discursos relacionados con las nuevas sensibilidades juveniles: la conciencia planetaria, la priorización de la vida cotidiana, el respeto "religioso" por el individuo, las causas sociales y la emergencia de nuevos territorios; delinea una veta interesante que invita a incursionar en nuevas lecturas sobre el mundo de los jóvenes en estos países signados por la marginalidad y al inequidad social. Es decir, que las nuevas sensibilidades no remiten al vacío de un océano de incertidumbre, por el contrario, de los confines de la propia sensibilidad se tejen nuevas redes sociales que prefiguran una sociedad de otra manera.

\section{A manera de conclusión}

Juntar dos categorías en apariencia distantes, no resulta una tarea fácil; sin embargo, constituye un ejercicio motivado por las ricas discusiones que se dieron al interior del proyecto de investigación que indaga sobre las emociones de los profesores de la UFPS. La comprensión de estas emociones requieren una indagación preliminar sobre los sujetos que van a dar la información sobre 112 el objeto del estudio. Por ello, uno y otro concepto ofrecen múltiples posibilidades para la realización del presente trabajo. Del mismo modo, permite una exploración de autores de referencia para el análisis de los datos.

Uno de ellos fue Michel Maffesoli, profesor de sociología en la Sorbona y director del Centro de Estudios sobre lo Actual y lo Cotidiano (CEAQ), autor de varios interesantes publicaciones, entre ellas, Lógica de la dominación (1977), La violencia totalitaria (1982), Elogio de la razón sensible (1997), El tiempo de las tribus, y el Crisol de las apariencias (2007), entre muchos otros trabajos de inusitado interés para quienes abordamos la categoría "juventud" como objeto de estudio. Maffesoli, es un autor de referencia para investigadores sociales que deseen abordar el presente, y saber cómo descifrar su manifestación más imperceptible y con mucha frecuencia marginal en la reflexión de Occidente: lo frívolo, la emoción, las pasiones, la apariencia, lo cotidiano, entre otros temas marginales de la filosofía tradicional.

Aunque el presente texto no centraliza su reflexión en un autor determinado, el artículo posee un fuerte motivador en el pensamiento de Maffesoli. Desde sus ideas sobre la contemporaneidad, se abordó el diálogo en torno a la tensión entre exclusión social y las nuevas sensibilidades juveniles, y desde allí, poniendo en contexto, la producción de importantes pensadores del tema juvenil como Germán Muñoz, Jesús Martín-barbero, Rossana Reguillo, Edgar Morin, Rodríguez, Gallart y Hopenhayn, entre otros.

De lo anterior se derivó un texto que pretendió la identificación de tensiones y encuentros entre exclusión social y nuevas sensibilidades, pero que sólo alcanza a trazar unas rutas aproximativas a un tema que merece más atención. Sin embargo, el escrito permite una interesante introducción al desarrollo del trabajo para la comprensión de las emociones de los docentes de la UFPS: Las culturas juveniles y el fenómeno de la exclusión, como referentes a la hora de indagar sobre los que estos jóvenes piensan sobre el sentir de sus maestros, y que motivan un nuevo interrogante: iqué piensan, qué sienten y que dicen los jóvenes universitarios sobre lo que piensan, sienten y enseñan sus docentes? 


\section{Referencias bibliográficas}

Arango, L. (2004) Jóvenes en la universidad: género, clase e identidad profesional. Bogotá: Siglo del hombre \& Universidad Nacional.

Barbero, Jesús Martín (2003). La educación desde la comunicación, Bogotá, Norma.

Bisquerra, R. (2003). Educación emocional y bienestar. Barcelona, Praxis.

Cubides, H. Y otros (editores) (2008). "Viviendo a toda": Jóvenes, territorios culturales y nuevas sensibilidades. Bogotá: Universidad Central (DIUC), Siglo del hombre editores.

Chabot, D. \& Chabot, M. (2009). Pedagogía emocional. México, Alfaomega.

De la Torre, S. \& Moraes, C. (2005). Sentipensar: fundamentos y estrategias para reencantar la educación. Málaga, Aljibe.

Gallart, M. (2000). Los desafíos de la integración social de los jóvenes pobres. Canadá: CIID.

Gardner, H. (1994). La teoría de las inteligencias múltiples. México, FCE.

Goleman, D. (1996). La inteligencia emocional. B. Aires, Javier Vergara editores.

Grosser Guillé, K. (2000). La juventud como mercancía. Universidad de Costa Rica, Revista electrónica Actualidades investigativas en educación, vol. 06, no 02.

Hopenhayn, M. (2004). La juventud en Iberoamérica: tendencias y urgencias, Chile: CEPAL-OIJ.

Maffesoli, M. (1997). Elogio de la razón sensible, Barcelona, Paidós.
, (2004). Juventud: el tiempo de las tribus y el sentido nómada de la existencia, México, Revistas de estudios sobre juventud, № 20, pp. 28-41.

, (2007). En el crisol de las apariencias, Madrid, Siglo XXI.

Melucci, A. (2001). Vivencia y convivencia; teoría social para una era de la información, Madrid, Trotta.

Morin, E. (2001). Los siete saberes necesarios del futuro, Bogotá, Magisterio.

Muñoz, G. (2002). Temas y problemas de los jóvenes en Colombia al comenzar el siglo XXI, U. De Manizales-CINDE, Revista latinoamericana de ciencias sociales.

(2006). La comunicación en los mundos de vida juveniles: hacia una ciudadanía comunicativa, tesis doctoral, Universidad de Manizales-CINDE.

Pedroza, R. y Villalobos, G. (2000). Entre la modernidad y la postmodernidad: jóvenes y educación superior, México, Educere, año 10, № 34, pp. 405-413. ISSN 0122-820X

Reguillo, R. (2008). Emergencia de culturas juveniles: estrategias del desencanto, Bogotá, Norma.

(2003). Las culturas juveniles, Revista brasilera de educación № 23.

, (2001). La gestión del futuro, México, Revista de estudios sobre juventud, año 05, № 15, pp. 6-25.

Rodríguez, E. (2002). Juventud, desarrollo social y políticas públicas en América Latina, Costa Rica, FLACSO. Recuperado de internet el 3 de noviembre de 2012 de: www.uia.mx/ campus/publicaciones/jóvenes/pdf/epieck2. pdf 
Sojo, C. (2000). Exclusión social y reducción de la pobreza en América Latina y el Caribe, Costa Rica, FLACSO.

Zarzuri, R. (2000). Culturas juveniles, revista última Década, № 13, pp. 81-96. 